\title{
GÊNERO, MILITÂNCIA FEMINISTA E CONSERVADORISMO NA AMÉRICA LATINA: ENTREVISTA COM FLÁVIA BIROLI, FLAVIA FREIDENBERG E VERÓNICA GAGO'
}

\author{
Por Marcia Candido, Simone Gomes e Talita Tanscheit ${ }^{2}$
}

Traduções e edições ao português e ao espanhol: Marcia Candido, Simone Gomes e Talita Tanscheit

Versão em inglês: Karine Belarmino, Clara Faulhaber, Ana Beatriz Martins, Lorena Miguel e Isadora Vianna Sento-Sé ${ }^{3}$

\section{Resumo}

Esta entrevista discute os desafios aos estudos de gênero e aos movimentos feministas frente à radicalização da direita na América Latina. Para tal, seleciona três interlocutoras de legitimidade acadêmica na região: Flávia Biroli, Flávia Freidenberg e Verónica Gago. A conversa é estruturada em dois pontos centrais: por um lado, debate a conjuntura de reações conservadoras e as alterações nos espaços públicos provenientes de mobilizações de mulheres por direitos e em defesa da democracia; por outro, confronta a definição de que os "estudos de gênero" constituem um tema específico das ciências sociais, qualificando as perspectivas feministas como vieses transformadores imprescindíveis à ampla compreensão dos fenômenos políticos e sociais.

\footnotetext{
1 Ver o currículo das entrevistadas no final do texto, p.41.

2 Marcia Candido é Doutoranda em Ciência Política no Instituto de Estudos Sociais e Políticos da Universidade do Estado do Rio de Janeiro (Iesp-Uerj) e bolsista da Coordenação de Aperfeiçoamento de Pessoal de Nivel Superior (Capes). E-mail: marciarangelcandido@gmail.com

Simone Gomes é Professora do Departamento de Sociologia e Ciência Política da Universidade Federal de Pelotas (UFPel) e do Programa de Pós-Graduação em Sociologia da mesma instituição. E-mail: s.ribeirogomes@gmail.com

Talita Tanscheit é Doutoranda em Ciência Política no Instituto de Estudos Sociais e Políticos da Universidade do Estado do Rio de Janeiro (Iesp-Uerj) e Professora Substituta no Departamento de Ciência Política da Universidade Federal do Rio de Janeiro (Ifcs-Ufrj). E-mail: talitastt@gmail.com

${ }^{3}$ Karine Belarmino é Doutoranda em Ciência Politica na University of Minnesota - MN, USA. E-mail: belar007@umn.edu

Clara Faulhaber é Mestra em Ciências Sociais Ciências Sociais pelo Programa de Pós-Graduação em Ciências Sociais da Universidade do Estado do Rio de Janeiro (PPCIS-Uerj). Email: clarafaulhaber@gmail.com

Ana Beatriz Martins é Doutora em Sociologia pelo Instituto de Estudos Sociais e Políticos da Universidade do Estado do Rio de Janeiro (Iesp-Uerj) e Pesquisadora na University of Sydney - Sydney, Au. E-mail: ana.martins@sydney.edu.au

Lorena Miguel é Doutoranda em Sociologia na Pontificia Universidade Católica do Rio de Janeiro (PUCRio. E-mail: lorenamsmiguel@gmail.com

Isadora Vianna Sento-Sé é Doutoranda em Ciências Sociais no Programa de Pós-Graduação em Ciências Sociais da Universidade do Estado do Rio de Janeiro (PPCIS-Uerj). E-mail: isadorasentose@gmail.com
} 
Marcia Candido, Simone Gomes e Talita Tanscheit: Caras, agradecemos pelo aceite à entrevista. O objetivo deste dossiê é discutir os rumos do feminismo na América Latina e as ameaças impostas pelo avanço do conservadorismo ao redor do mundo. Escolhemos as três por considerá-las referências singulares nesses assuntos, mas também por identificarmos similitudes em suas trajetórias. A primeira questão que apresentamos, portanto, diz respeito às escolhas intelectuais de vocês. A inserção no campo de estudos de gênero não parece ter sido a primeira opção no caminho de formação das três. Quais eventos motivaram o aprofundamento de vocês na temática?

Flávia Biroli: Eu tenho uma trajetória atípica, estudei jornalismo na graduação, fiz mestrado e doutorado na área de História, e desde 2003 atuo na área de Ciência Política, como professora do Instituto de Ciência Política da Universidade de Brasília (IPOL-UnB) e inserida academicamente nessa área não só como professora, mas nas minhas pesquisas, publicações, diálogos. Meu tema principal de pesquisa foi comunicação e politica até 2006. E foi por meio dele que cheguei aos estudos de gênero, quando passei a trabalhar com um colega do IPOL da UnB, Luis Felipe Miguel, em uma pesquisa sobre mulheres na política e no noticiário político, inserida no debate sobre subrepresentação política feminina. Tive que olhar meu currículo para me lembrar das datas e com isso percebi que a partir de 2009 a maior parte das minhas publicações passaria a ser sobre mulheres, gênero e politica. Inicialmente, mídia e representação politica, pela parceria com Luis Felipe, foram os principais temas. Depois, o conceito de autonomia no debate teórico feminista, cada vez mais conectado ao debate sobre divisão sexual do trabalho e cuidado. O que importa mais, talvez, é que, quando comecei a trabalhar com pesquisas sobre gênero e política, minha compreensão de todo o debate sobre democracia rapidamente se deslocou. O fato de que as teorias feministas tornam visiveis exclusões que só se explicam pela conexão entre as categorias mobilizadas pelas pesquisas, as hierarquias de gênero no cotidiano e as hierarquias de gênero na política é sua maior força, na minha compreensão. Outro ponto é que lutas e teorias feministas se constituem reciprocamente. 
No meu caso, o envolvimento com o feminismo se deu na medida em que mergulhei no debate teórico e nas pesquisas.

Flávia Freidenberg: Por muitos anos, entendi a Ciência Política como uma disciplina alheia aos debates feministas. Eu não tinha uma perspectiva de gênero a partir da qual abordar o estudo do poder e do sistema político e reiterava, repetidamente, que a ciência deveria ser indiferente aos debates ideológicos (ignorando que, ao dizer isso, já expressava uma ideologia). Eu não estava interessada nesses temas e não acreditava que fossem estudos necessários para o desenvolvimento do conhecimento científico. Durante a primeira parte da minha carreira, eu desconhecia e ignorava as desigualdades de gênero e não as considerei fundamentais para minha formação, as leituras que eu tinha que fazer ou minha pesquisa. No decorrer de toda essa etapa, eu fui muito ingênua acreditando que essas questões - vinculadas às desigualdades de gênero e ao papel das mulheres na sociedade - eram propriedade da sociologia ou, especificamente, dos estudos de gênero.

Eu me formei em uma escola onde a análise do poder e funcionamento do sistema político prestava pouca atenção à presença ou ausência de mulheres. A politica era analisada como uma "coisa de homens" e, fundamentalmente, desde uma perspectiva adrocêntrica. Não havia muitas autoras mulheres, ou pelo menos não as líamos; minhas professoras eram poucas, e a maioria estava sempre em posições secundárias (como assistentes de professores homens). Nesse sentido, demorei a perceber que tanto a "ciência" quanto a "política" não conseguiram escapar à articulação da ordem social construida assimetricamente entre homens e mulheres.

Minha mudança foi, fundamentalmente, uma mudança de "lentes" (de óculos), de perspectiva a respeito do modo como o conhecimento é abordado e exercido. Minhas próprias experiências pessoais em relação aos tetos de vidro nas instituições universitárias (e até mesmo os meus próprios tetos de cimento ou autolimitações do que eu era capaz de fazer), por exemplo, tiveram um impacto importante sobre a minha maneira de pensar e exercer a Ciência Política. Também o fato de que vários dos meus colegas (homens e mulheres) tinham essa perspectiva e foram me ajudando a "remover o véu" que eu tinha 
em meus olhos e que me impedia de ver com óculos de gênero. Atualmente, continuo a vivenciar um processo de mudança, desconstrução e desaprendizado diário, cada vez mais interessado em descobrir e exercer uma ciência política feminista.

Me sinto cada vez mais cômoda adotando posturas vinculadas ao "neoinstitucionalismo feminista", como apontaram autoras como Jay Lovenduski ou Fiona Mackay, para entender melhor as relações de poder e os vínculos entre os atores. Não se trata apenas de estudar problemas de representação política (como faria uma ciência política de gênero), mas de estudar essa representação pensando na maneira pela qual as desigualdades de gênero supõem assimetrias no acesso e exercício do poder político. Acredito que neste espaço temos muito a fazer a partir de pesquisas comparadas para pensar em melhores ações (e politicas) que contribuam para "desgenerizar" as instituições e decisões públicas.

Verónica Gago: As minhas preocupações teóricas e pesquisas estiveram centradas desde o principio no debate sobre as formas de trabalho no capitalismo contemporâneo. Desde então, sem dúvidas teve para mim vital importância toda a temática ligada ao que se conhece como "feminização do trabalho" e do trabalho migrante; para, de forma mais ampla, entender as sequências de lutas históricas que produzem antagonismo e forçam em momentos diversos a ocorrência de rupturas sociais e, em particular, a confrontação das relações de exploração. Isto é inevitável, na minha opinião, com um pensar desde a América Latina, e desde a Argentina em particular, na hora de situar a dimensão transnacional tanto dos processos de luta, de seus corpos e territórios em conflito, como das renovadas formas imperiais. Os debates sobre neoliberalismo em que eu fui me adentrando, por sua vez, e em particular os que me parecem mais inspiradores em termos conceituais, põem como chave a produção da subjetividade. Seguindo a linha explorada por Michel Foucault, mas também pelo debate feminista e pós-marxista, para mim é inevitável chegar nestas questões que chamam de "gênero", mas de um modo específico: através de quem pensa a articulação entre capitalismo e patriarcado como a lógica específica de valorização moderna-colonial. Em 
nosso continente temos um arsenal riquíssimo de conceitos e de experiências, de levantamentos e de teorizações, que armam uma forma concreta de perseverar e intervir nestas questões. Quer dizer, desde a América Latina não podemos deixar de nos situar no que historicamente "não" tem sido reconhecido como trabalho e nisto as dimensões de raça e de gênero são vetores constitutivos do que podemos problematizar, do que permanentemente aparece como espaço de exploração, subordinação e, por sua vez, de revolta e inovação coletiva.

Mas o meu desejo cognitivo, para chama-lo de alguma forma, vem nutrido pela minha militância política e pelo meu trabalho na editora independente Tinta Limón. Estive envolvida em processos políticos desde que era estudante na universidade, para logo ser parte de experiências de pesquisa militante autônoma e em relação com diversos movimentos sociais, que desde o início deste século tem contestado por diversas vezes a legitimidade política do neoliberalismo. Logo me comprometi mais diretamente com as lutas feministas, o que me levou também a reformular minhas preocupações de trabalho nesta perspectiva, ainda assim era algo que eu já vinha trabalhando, lendo e pesquisando.

Deste modo quero dizer duas coisas: que a orientação das minhas inquietudes teóricas sempre se desenvolveu no interior de processos de militância política e, logo, que as lutas feministas tem sido uma inspiração prática no modo de desdobrar estas investigações.

Sinto algumas linhas de continuidade ao longo do tempo. Por exemplo, a pergunta metodológica e política pelo caráter situado do pensamento, e, portanto, de sua materialidade corporal. Neste sentido, um pensar situado é inevitavelmente um pensar feminista. Porque se algo nos tem ensinado a história das lutas, de suas conquistas e fracassos, é que a potência do pensamento sempre tem corpo. E que esse corpo é uma composição constante e coletiva (mesmo quando é individual), que remonta experiências, expectativas, recursos, trajetórias e memórias. Um pensar situado é inevitavelmente parcial. Parcial não significa uma pequena parte, um fragmento ou uma lasca. Mas sim é um retalho em uma bricolagem, uma montagem específica. Como tal, funciona como um ponto de entrada, uma 
perspectiva, que singulariza uma experiência. Estes elementos sempre me inspiraram para pensar teoria política feminista porque desvelam o caráter do masculino como universal que está nas origens de toda a "ordem" política. Creio que por estas questões numa me especializei "só" em gênero e, por isso, minhas interlocuções teóricas e politicas são também diversas. Mas a perspectiva feminista, como sabemos, não é somente sinônimo de tematização de gênero, mas um modo epistêmico e político de abordar todas as práticas, os focos de experiências, as dinâmicas de insubordinação e as maneiras de elaborar conhecimento.

Candido, Gomes e Tanscheit: Além de desfrutar de pouca legitimidade na academia, os estudos de gênero têm constituido um dos principais alvos de agressões e censura de atores politicos conservadores. Tendo em vista o endurecimento das intervenções dos novos governos de direita nas universidades públicas, quais os principais desafios às professoras envolvidas com movimentos feministas? Vocês podem comentar o que significa a noção de “ideologia de gênero" nos seus respectivos países e de que maneira ela é usada como artificio para perseguir pesquisadoras?

Biroli: Tivemos e temos ainda muita dificuldade para que as e os colegas entendam que os estudos de gênero não são estudos sobre as mulheres ou sobre questões específicas: são sobre a democracia e seu funcionamento, sobre as relações de poder e as hierarquias que organizam o acesso a recursos e as garantias seletivas para as pessoas. A reação conservadora parece ter entendido isso. Combatem os estudos de gênero pelo seu potencial de deslocar hierarquias naturalizadas, de ampliar o debate público sobre opressões e formas de exploração que estão na base de privilégios. Eles de fato afetam, justamente por isso, "as famílias", "a ordem" e "a natureza" como dispositivos hierárquicos e de privilegiamento de alguns, em detrimento de outros (de outras, nesse caso). Sabe o que é essa suposta natureza de que se sentem tão saudosos? É uma ordem social disciplinar, que tem no trabalho gratuito das mulheres e no controle dos seus corpos e da sua capacidade reprodutiva uma base fundamental. A campanha contra a chamada "ideologia de gênero" é 
transnacional e tem contado com organizações que angariam recursos e declaram abertamente suas intenções: incidir sobre o Estado nos contextos nacionais e sobre as organizações internacionais, o sistema ONU mais especificamente, de modo a deter uma agenda que produz efeitos e desloca as hierarquias de gênero. Estão particularmente preocupados com a socialização das crianças. Há uma questão geracional relevante. Querem proteger a si mesmos das mudanças, mas empunham a bandeira da proteção à infância como forma de mobilizar públicos, em um momento de transformações e de inseguranças. Têm também reproduzido uma narrativa: a de que o feminismo já foi "bom", quando lutou pelo direito das mulheres a salários e ao voto. Mas desde meados do século XX - e localizam em Simone de Beauvoir o ponto de origem - foi tomado por radicalismos. E teria até se esquecido do que são mulheres! Não aceitam, sobretudo, a desnaturalização de papeis fundados no sexo biológico.

Freidenberg: A ideologia de gênero não existe como tal. Pelo contrário, costumo pensar nisso como uma engenhoca dos setores conservadores (dentro e fora da academia) para reproduzir uma rachadura (uma divisão) contra as pessoas que defendem a igualdade entre homens e mulheres e aqueles que não a defendem. A ideologia de gênero é parte de uma estratégia para neutralizar os movimentos que buscam expandir os direitos. No espaço acadêmico em que atualmente desenvolvo minha profissão, não me sinto especialmente ameaçada por defender essas posturas, por escrever e pesquisar a participação e a representação politica das mulheres ou por assumir um compromisso ativo com a defesa dos direitos politicos eleitorais das mulheres. Algumas vezes me fazem perguntas ou comentários depreciativos, mas entendo que minha tarefa é fazer pedagogia e acrescentar mais e mais vozes à luta por direitos.

No México, os atores conservadores são ativos, promovendo "sua" ideologia de gênero, mas, ao menos que eu conheça, ou possa registrar de maneira expressa e direta, eles não estão perseguindo pesquisadoras de ciências sociais que promovam a defesa dos direitos das mulheres. Mesmo assim, existem muitos obstáculos, a pesquisa [de gênero] ainda não faz parte 
do mainstream da disciplina e os diálogos geralmente seguem sendo entre mulheres. A ciência política continua sendo conservadora (como assinalou Jay Lovenduski); tem resistido a temas e enfoques feministas e foi construída sobre noções conceituais, teóricas e metodológicas que envolvem um profundo viés de gênero masculino, reproduzindo "símbolos generificados da expertise" (como denominou Johanna Kantola em seus estudos sobre a Finlândia) em relação a quem é o especialista, quais temas e quem são marginais na disciplina ${ }^{4}$.

$\mathrm{Na}$ prática, as mulheres continuam sub-representadas como professoras em departamentos universitários e sua participação diminui na medida em que progridem as posições de poder na gestão acadêmica ${ }^{5}$. Elas também são invisibilizadas nas conferências magistrais dos congressos, nas referências e citações a suas publicações acadêmicas, nos comitês editoriais ou nos conselhos técnicos das associações profissionais da disciplina e, inclusive, nas entradas dos perfis da Wikipedia, onde quase não aparece a categoria "cientista política" e a presença de cientistas latino-americanas é marginal6.

Gago: Vivemos um momento de contraofensiva: quer dizer, de reação à força demonstrada pelos feminismos na região. É importante remarcar a sequência: a contraofensiva responde a uma ofensiva, a um movimento anterior. Isto supõe localizar a emergência dos feminismos em relação ao posterior giro

\footnotetext{
4 KANTOLA, Johanna. (2008). "Why Do All the Women Disappear? Gendering Processes in a Political Science". Departament. Gender, Work and Organization, vol.15, n.2, mar. 2008.

KANTOLA, Johanna. (2015). "Political Science as a Gendered Discipline in Finland". European Political Science, n.14, p.79-86.

5 Panoramas sobre diversidade no quadro de professores de Ciência Politica em contextos nacionais ainda são raros. Para ver um levantamento sobre o cenário brasileiro, consultar: CANDIDO, Marcia. FERES JÚNIOR, João. CAMPOS, Luiz Augusto. (2019, no prelo). "Desigualdades na elite da Ciência Politica Brasileira”. Civitas - Revista de Ciências Sociais. Dossiê - História, desenvolvimento e ensino da Ciência Politica. Na América Latina, de modo mais geral, ver: CARPIUC, Cecilia. (2016). "Women and Diversity in Latin American Political Science". European Political Science.

6 Para dados sobre a sub-representação de mulheres entre as referências na Ciência Politica, ver, por exemplo, HARDT, Heidi. et al. (2019). “The Gender Readings Gap in Political Science Graduate Training”. The Journal of Politics. No caso das associações profissionais consultar ABU-LABAN, Yasmeen. SAWER, Marian. ST-LAURENT, Mathieu. (2018). IPSA Gender and Diversity Monitoring Report. Disponivel em: https://www.ipsa.org/sites/default/files/2018-

06/IPSA\%20Gender\%20and\%20Diversity\%20Monitoring\%20Report\%202017_FINAL\%20\%28web\%20v ersion\%29.pdf
} 
fascista na região e em nivel global. Se desprendem daqui duas considerações. Em termos metodológicos: localizar a força dos feminismos em primeiro lugar, como força constituinte. Em termos políticos: afirmar que os feminismos põem em marcha uma ameaça aos poderes estabelecidos e ativam uma dinâmica de desobediências que tentam conter, contrapondo formas de repressão, disciplinamento e controle em várias escalas. A contraofensiva é um chamado à ordem e sua agressividade é medida em relação à percepção de ameaça ao que se está respondendo. Por isso, a feroz contraofensiva desatada aos feminismos nos dá uma leitura ao contrário, reversa, da força da insubordinação que tem sido percebida como já acontecendo; e, por sua vez, com possibilidade de radicalização.

Através do conceito de "ideologia de gênero" hoje é sintetizada uma autêntica cruzada encabeçada pela igreja caótica e outros fundamentalismos religiosos contra a desestabilização feminista. Esta "cruzada", depois de ser elaborada nas cúpulas do poder teológico, busca fabricar seu "movimento social" para disputar corpo a corpo nos territórios que têm sido comovidos pelas lutas feministas. Na Argentina, há um ponto de intensificação desta contraofensiva conservadora e é a "onda verde" (quer dizer, uma verdadeira mobilização de massas) a favor da legalização do aborto, que durante 2018 inundou as ruas e dispersou seu impacto em nivel mundial.

Os argumentos religiosos aqui têm tentado traçar uma distinção de classe que justificaria que as mulheres pobres não têm mais opção do que ser católicas e conservadoras, porque só têm como opção a maternidade. Deste modo, abortar (quer dizer, decidir sobre o desejo, a maternidade e a própria vida) tenta ser reduzido a um gesto excêntrico das classes média e alta (que, claro está, pode por em jogo recursos econômicos diferentes). O argumento "classista", que com certeza existe em termos de possibilidades diferenciadas para aceder a um aborto seguro, é invertido: passa a funcionar como justificativa da clandestinidade. O direito a decidir, para a Igreja, deve permanecer assim distante dos bairros populares. A "ideologia de gênero", através de seus porta-vozes, se autoproclama como antineoliberal. Mas a "ideologia de gênero" propõe que há que combater o neoliberalismo através de um retorno à família, ao trabalho disciplinado como único provedor de 
dignidade, e a maternidade obrigatória como asseguradora do lugar da mulher.

O neoliberalismo, assim, é definido como uma política de um modo de subjetivação da pura desagregação da ordem familiar e do trabalho, quer dizer, patriarcal. Que essa ordem seja patriarcal, contudo, não é problematizado. Chegamos a uma espécie de contradição lógica: pode o antineoliberalismo ser sustentado em uma ordem patriarcal, cuja estrutura biologicista e colonial é indissimulável? Isso é justamente o que os feminismos têm deixado evidente em sua radicalização massiva: não há capitalismo neoliberal sem ordem patriarcal e colonial.

Junto à contraofensiva eclesial estamos vendo ser aprofundada uma contraofensiva econômica. Nesta articulação vemos um papel fundamental do neoliberalismo atual: o aprofundamento da crise de reprodução social que é sustentada por um incremento do trabalho feminino, que substituiu as infraestruturas públicas e termina implicado em dinâmicas de superexploração. A privatização de serviços públicos ou a restrição de seu alcance faz com que estas tarefas (saúde, cuidado, alimentação etc) devam ser supridas pelas mulheres e os corpos feminizados como tarefa não remunerada e obrigatória. Várias autoras têm destacado o aproveitamento moralizador propagado com esta mesma crise reprodutiva. Aqui surge uma chave fundamental: as bases de convergência entre neoliberalismo e conservadorismo.

Como funciona isto no ajuste contra as instituições universitárias e de pesquisa? Há um corte generalizado no financiamento (pensemos que o governo de Mauricio Macri no ano passado eliminou 13 Ministérios, entre eles o de Ciência e Tecnologia). Mas sem dúvidas, em termos de pesquisa, as áreas mais afetadas são as das ciências sociais, e de maneira ainda mais notável as vinculadas aos estudos de gênero. Isto vem acompanhado de campanhas midiáticas onde esses temas de investigação são ridicularizados e tratados como "supérfluos" ou inúteis. Ao mesmo tempo, há uma tentativa de reconciliar o feminismo e o neoliberalismo pelo lado das propostas de ONGs e de ofertas de endividamento (via microcréditos e empréstimos bancários), 
como maneira de traduzir e neutralizar a dimensão mais desobediente dos feminismos mobilizados.

Candido, Gomes e Tanscheit: No que toca à vida das mulheres, diversos países latino-americanos são lideres em violência contra o gênero feminino. Somadas às questões da vida privada, com severos indices de agressões internas à família, a participação política das mulheres - no plano institucional ou nos movimentos sociais -, é frequentemente atravessada por opressões. Como as pesquisas feministas têm contribuido para elucidar essas dinâmicas?

Biroli: As pesquisas feministas têm explicitado essas violências como problemas políticos. Esse é um ponto fundamental. A violência cotidiana naturalizada tem sido também historicamente despolitizada: "as mulheres não se dão ao respeito", "ela queria o que, agindo como agiu”, “as mulheres não querem participar da política”. Vejam que os estereótipos que justificam agressões organizam, ao mesmo tempo, o cotidiano da violência, as barreiras à participação igualitária e a retirada sistemática de recursos que permitiram às mulheres incidir eficazmente nas normas. Outro ponto importante é que os estudos feministas, mesmo aqueles de vertente institucionalista, analisam a relação entre as instituições e as práticas informais que reproduzem as desigualdades e as barreiras à participação das mulheres. E o fazem validando as experiências das mulheres, de diferentes mulheres, nessas relações. Esse desvendamento de práticas informais de marginalização e opressão se dá pela construção de novas categorias analíticas, que permitem ver novos problemas, na medida em que é feito levando-se em conta a metade da população à qual se recusou a condição de sujeito político e de sujeito de conhecimento, historicamente.

Freidenberg: A violência política em razão de gênero tem sido na maioria dos países latino-americanos uma das consequências indesejáveis das reformas politicas eleitorais realizadas na região para incrementar a participação politica das mulheres. Desde 1991, os países do eixo fizeram pelo menos 37 reformas eleitorais para obrigar os partidos políticos a colocar mulheres em 
instituições democráticas. O aumento de mulheres nas câmaras legislativas na América Latina e no Caribe passou de 9\% para quase 30\% em 2018 (segundo dados da CEPAL) ${ }^{7}$.

A pesquisa em Ciência Política tem contribuído para identificar, visualizar e conceituar essa violência. No México, muito tem sido discutido sobre este tema. Trabalhos como os de Mona Lenna Krook, Juliana Restrepo, Maria del Carmen Alanis ou Jennifer Piscopo, somados ao das autoridades eleitorais (juizes e funcionários), foram fundamentais na identificação do que é a violência política contra mulheres, justamente porque elas são mulheres. Também agências intergovernamentais (como a Comissão Interamericana de Mulheres da OEA ou a ONU Mulheres), as Redes de Mulheres (como a Red de Mujeres en Plural, a REPARE e a Asociación de Mujeres Guerrerenses AC) e as organizações da sociedade civil contribuíram para a identificação das práticas violentas e simulações que os partidos exercem contra as mulheres.

Gago: As investigações feministas tem colocado em jogo outra economia da visibilidade para as violências. Um ponto central das mobilizações destes anos, especialmente com o exercício político da greve, é construir um diagnóstico feminista do entrecruzamento das distintas violências e difundilo em todos os espaços: educativos, políticos, institucionais, comunitários etc.

Neste sentido, a reconceitualização da violência machista tem sido chave para o movimento feminista dos últimos anos de dois modos: em primeiro lugar, pluralizando sua definição - deixamos de falar "somente" da violência contra as mulheres e corpos feminizados para colocá-la em relação a um conjunto de violências sem as quais esta não se explica, e menos ainda é compreendido com respeito ao seu incremento histórico. Falar das violências desde o feminícidio e o travesticídio os localiza como o seu ponto culminante, mas impõe um desafio: não nos fecharmos ali, em sua contabilidade necropolítica.

\footnotetext{
7 Disponivel em: https://oig.cepal.org/pt/indicadores/poder-legislativo-porcentagem-mulheres-no-
} orgao-legislativo-nacional-camara-baixa-ou 
Dessa forma, dar conta da pluralização das violências é estratégico: é uma forma concreta de conexão que produz inteligibilidade e, portanto, permite um deslocamento da figura totalizante da vítima. Pluralizar não é só fazer uma quantificação, uma lista, das violências. É algo muito mais denso: é um modo de cartografar a sua simultaneidade e a sua inter-relação. É conectar os lares explodidos com as terras arrasadas do agronegócio, com as diferenças salariais e o trabalho doméstico invisibilizado; vincular a violência do ajuste e a crise com os modos em que estas são enfrentadas desde um protagonismo feminizado das economias populares; e relacionar tudo isto com a exploração financeira pelo endividamento público e privado; atar as formas de disciplinamento das desobediências às mãos da repressão lisa e terrena do Estado e à perseguição dos movimentos migrantes, também à maneira em que são encarceradas as mulheres mais pobres, criminalizando economias de subsistência e as que praticam o aborto, com a marca racista de cada uma destas violências. Nada nesta rede de violências é óbvio: rastrear os modos de sua conexão é produzir sentido, porque visibiliza a maquinaria de exploração e extração de valor que implica limiares de violência cada vez maiores e que tem um impacto diferenciado (e por isso estratégico) sobre os corpos feminizados.

Candido, Gomes e Tanscheit: É notável que tanto a produção acadêmica quanto a militância feminista nas ruas foi renovada nos últimos anos. Quais continuidades e rupturas vocês observam na produção das gerações atuais em comparação às anteriores? E as diferenças da militância nas ruas? Como conciliar estas gerações e suas estratégias de atuação?

Biroli: Os feminismos se tornaram mais capilarizados nos anos 2000. Há alguns aspectos que penso serem bastante relevantes nessa capilarização: multiplicaram-se as organizações, que aparecem mais na forma de coletivos do que dos movimentos que conhecíamos (e elas, justamente por isso, não atendem aos mesmos padrões organizacionais); a agenda feminista está presente em diferentes espaços e, por isso, é mobilizada de maneira ainda mais plural e diferenciada; os ganhos de legitimidade das perspectivas 
feministas despertaram reações que procuram colocar em xeque justamente o que tem sido mais eficaz, que é o fato de que os fundamentos da agenda da igualdade de gênero se popularizaram e parecem mesmo ser um traço do público - público como multiplicidade e conflitos - no nosso tempo. O fato de que essa capilarização possa ter sido potencializada pela ação institucional de feministas que atuam há algumas décadas - essa é uma hipótese que considero plausivel, pensando nas organizações internacionais, na incorporação da agenda nos contextos institucionais nacionais - não leva as feministas que passaram a assim se identificar e atuar conjuntamente nos últimos anos a reconhecer como relevante a ação institucional e seus meios e espaços. Penso que há muita potência nos feminismos atuais, mas seria importante debatermos em que medida o diagnóstico do enfraquecimento das democracias e dos riscos que apresenta para as mulheres tem se transformado em ação estratégica para construir democracias. E o que isso significa? $\mathrm{Na}$ minha perspectiva significa fortalecer partidos políticos, modificando-os. Construir bases amplas para a luta politica por direitos e por sociedades mais igualitárias e nas quais as relações de cuidado estejam no cerne das preocupações politicas, o que implica necessariamente a crítica ao capitalismo neoliberal. Mas não há nem haverá unidade política de ação - e esse não é o problema. O feminismo sempre foi uma batalha do cotidiano, que se desdobra em ações estratégicas para modificar as instituições e construir direitos. São nessas estratégias que as diferenças geracionais talvez se tornem mais visiveis porque as que atuam há mais tempo têm percepções da luta nos espaços institucionais que talvez sejam bastante distintas daquelas que estão entre os novos coletivos. As ações de maior sucesso, na minha percepção, são aquelas que têm sido capazes de conectar a potência dessa luta cotidiana à organização para incidir nas instituições, barrar violências e avançar direitos. Seria preciso analisar caso a caso, mas não são essas justamente ações que têm, na sua construção e no seu curso político, produzido a interação, o diálogo, o agir conjunto de gerações diferentes, a busca por alternativas institucionais? Não foi isso que aconteceu na luta pelo direito ao aborto na Argentina? Na mobilização contra o PL5069 e na construção do \#EleNão no Brasil? 
Freidenberg: Para mim não é muito fácil comparar momentos e fases porque minha experiência é recente. O que nossas professoras (Line Barreiro ou Alejandra Massolo) dizem é que este é um momento histórico de mobilização nas ruas (Brasil, Argentina, Chile) e também de expansão dos direitos legais (México, Costa Rica, Bolívia ou Equador). Elas também nos alertam sobre a necessidade de continuar trabalhando para que as conquistas se mantenham e perdurem, pois as ondas de expansão de direitos são sempre acompanhadas de ofensivas que buscam eliminar esses mesmos direitos.

Gago: A dimensão massiva tem muito a ver com a composição intergeracional do movimento. Assistimos a convergência de distintas camadas ou estratos de militâncias e de debates que são atualizados como parte da transversalidade política.

Durante muito tempo o feminismo foi entendido em sua variante mais institucional e/ou acadêmica, historicamente dissociado de processos de confluência popular. O que vemos hoje é que o feminismo virou uma presença e uma força concreta em uma multiplicidade de espaços e territórios. Há linhas genealógicas fundamentais que têm feito possivel esta expansão atual. Na Argentina, ressaltamos quatro: (1) a história de luta dos direitos humanos desde os anos 70, protagonizado pelas Mães e Avós da Plaza de Mayo; (2) as mais de três décadas do Encontro Nacional de Mulheres (agora plurinacional de mulheres, lésbicas, trans e travestis); (3) a irrupção do movimento piquetero (de trabalhadorxs desocupadxs), de um protagonismo também feminizado na hora de enfrentar a crise social do começo do século; (4) e uma longa história de movimento de dissidências sexuais que vão da herança da Frente de Liberação Homossexual (FLH) dos anos 70 à militância lésbica pelo acesso autônomo ao aborto e do ativismo trans, travesti, intersexual e transgênero, que revolucionou os corpos e as subjetividades do feminismo contra os limites biologicistas.

A transversalidade conquistada a partir da organização da greve atualiza estas linhas históricas e as projeta em um feminismo de massas, arraigado nas lutas concretas das trabalhadoras da economia popular, nas 
migrantes, nas cooperativistas, nas defensoras do território, nas precarizadas, nas novas gerações de dissidências sexuais, nas donas de casa que renegam o confinamento, na luta pelo direito ao aborto, que é a luta ampliada por autonomia do corpo, nas estudantes mobilizadas, nas que denunciam os agrotóxicos, nas trabalhadoras sexuais. Põem um horizonte em comum em termos organizativos que funciona como catalizador prático.

O poderoso é que ao integrar esta multiplicidade de conflitos se redefine a dimensão de massas desde práticas e lutas que têm sido historicamente definidas como "minoritárias". Com isto, a oposição entre minoritário e majoritário é deslocada: o minoritário toma escala de massas como vetor de radicalização ao interior de uma composição que não para de ser expandida. É desafiada desta forma a engenharia neoliberal de reconhecimento das minorias e de pacificação das diferenças.

Candido, Gomes e Tanscheit: O movimento feminista tem sido um dos mais vigorosos atores de protestos de rua contra a ascensão da direita na América Latina e no mundo. Algumas autoras chegam a definir esse momento como parte de uma "quarta onda" do feminismo. Em contraste, diversas análises de cientistas politicos e sociólogos tradicionais continuam a ignorar o protagonismo das mulheres nos processos politicos e sociais em curso, ou quando consideram o grupo, tendem a afirmar ideias pouco dialógicas com a produção dos estudos de gênero. No Brasil, um exemplo recente disso foi a sugestão de causalidade, por parte de alguns acadêmicos, do aumento de votos em Bolsonaro em função das manifestações contrárias de mulheres no \#EleNão. Em que medida vocês avaliam o crescimento da extrema-direita como uma resposta à atuação dos movimentos sociais e suas continuas demandas pela expansão de direitos? Como vocês, pesquisadoras do tema, consideram o impacto dos protestos feministas nas transformações recentes do espaço público?

Biroli: Os movimentos feministas acentuaram sua presença pública em um momento de recesso democrático na América Latina e em outras partes do mundo. Atores coletivos que tiveram papel central na construção dos regimes democráticos no pós-guerra, e penso sobretudo nos movimentos sindicais, 
reduziram sua capacidade de mobilização. Os partidos politicos estão em crise profunda. Parte dos analistas continua olhando para o que deixou de ser sem se dar conta de que não têm buscado categorias para analisar o que é. Por isso, conectam as dificuldades pelas quais passam as esquerdas pelo mundo, por exemplo, ao que definem como "movimentos identitários", sem pudor ao explicitar visões de que uma suposta "fragmentação das agendas" ou “provocação aos conservadores" poderia justificar silenciamentos. O \#EleNão não levou a extrema-direita à presidência no Brasil nem foi capaz de impedir que ela vencesse as eleições. Até o fim, houve uma clivagem de gênero nas intenções de voto, mais acentuada entre os estratos mais jovens da população, mas ela não foi capaz de impedir a vitória da extrema-direita. O que o \#EleNão fez foi colocar nas ruas a misoginia como problema politico, a violência contra as mulheres como agenda central, e não lateral, numa eleição. Foi um movimento de forte repercussão - e que foi assim percebido por aqueles que, em operações nada espontâneas, montaram uma apresentação desse movimento com o objetivo de evitar a identificação de setores mais conservadores da sociedade. Penso nas imagens falsas que circularam pelas redes, pelo Whatsapp. Os movimentos feministas são atores nas disputas políticas mais centrais hoje. Não porque a política tenha se tornado "identitária". Mas porque eles têm sido capazes de mobilizar por democracia, de colocar em xeque as relações de trabalho e os padrões atuais de captura do Estado e da vida pelas grandes corporações. Todo o movimento feminista poderia ser assim definido? Não, claro que não. Mas em algum momento fizemos essa pergunta sobre os movimentos de trabalhadores e sindicais, esperando que sua legitimidade fosse derivada de uma unidade crítica radical? Quem o fez, o fez como estratégia politica para minar essa mesma legitimidade.

Freidenberg: De fato, o movimento feminista é um dos atores mais democratizantes e ativos da história recente da América Latina. Nossas professoras feministas costumam dizer que cada vez que houve uma expansão de direitos para as mulheres, uma grande onda de reformas e avanços, houve forte resistência e, com isso, a possibilidade de retrocessos. Eu acho que o 
interessante é ver que existem vários repertórios de ação e protesto (não é de uma forma única), que os direitos pelos quais se lutam também são diferentes (em alguns movimentos são direitos reprodutivos e em outros direitos políticos e eleitorais) e que a força das alianças entre o amplo movimento de mulheres, junto às políticas e acadêmicas, é fundamental para o avanço desses direitos. Enquanto nos países do Sul, o movimento está no ciberfeminismo e nas ruas (Argentina, Chile), no Norte (México) se está lutando a partir das redes sociais, do lobbying e do litígio estratégico. As estratégias são ferramentas para alcançar os objetivos: aprofundar a democratização da democracia.

Gago: Como dizia antes, creio que é importante caracterizar a "contra" ofensiva em sua dimensão de "reação" aos feminismos atuais que em nossos países se destacam por três características: serem massivos, radicais e construírem agenda política tanto de base como institucional. Não obstante, como vocês dizem, há um insistente menosprezo por parte de muitas análises e teorizações em respeito ao impacto transversal que estão tendo os feminismos como movimento antineoliberal. Por um lado, tentam colocar o feminismo em uma área temática, uma sorte de fio epistêmico e de confinamento político, que tem como objetivo não creditar nem legitimar sua capacidade expansiva, sua forma de enunciação política e seu impacto em todas as dimensões do sistema político e dos espaços de pensamento.

Aqui tem existido argumentos que dizem que as mobilizações não têm capacidade nem eficácia para prevenir ou diminuir os feminicídios, colocando, portanto, em dúvida a sua função. Quer dizer: é comparado o aumento da mobilização feminista ao o aumento dos crimes e traçada uma relação causal direta, por um lado; e, por outro, o objetivo é "constatar" a "ineficácia” da mobilização mesma para contrariar a violência feminicida.

Desde os discursos da psicologia se fala em uma "ilusão" mimética da força das mulheres, lésbicas, trans e travestis que as faria tomar atitudes de "empoderamento" que as levaria a morte. O argumento menciona um "efeito contágio" do coletivo que, mais que lograr proteger as vítimas, as expõe ainda mais. De uma forma similar tentaram ler a massiva mobilização do "\#EleNão" no Brasil, a qual se quis culpabilizar o posterior triunfo nas urnas do ultra fascista Jair Bolsonaro. A linguagem foi também psicológica-culpabilizante: a 
marcha das mulheres e LGBTQI "despertou o monstro", foi dito também aqui. A efervescência multitudinária fica desprestigiada como falsa, enganosa e, sobretudo, de risco (o "contágio" de um vírus"): leva a confiar em uma experiência de força coletiva que não faria mais que ser revelada como perigosa e ilusória. Ou ainda mais: contraproducente. Ou seja, a estratégia é dupla: culpabilização e "impotenciação".

Então, acredito que nós feministas lançamos uma pergunta fundamental: como explicar a aliança atual entre neoliberalismo e conservadorismo?

O tipo de fascismo atual, essa especial convergência entre neoliberalismo e conservadorismo extremo, é uma política que constrói um inimigo "interno". Este inimigo interno está encarnado por quem historicamente tem sido considerado estrangeiro no âmbito "público" da política. Hoje o inimigo interno que o fascismo aponta é o movimento feminista, em toda a sua diversidade, e xs migrantes, como sujeitos também feminizados. O fascismo atual lê nossa força de movimento feminista, antirracista, antibiologicista, antineoliberal e, portanto, antipatriarcal.

A agressividade do fascismo atual, entretanto, não pode fazer com que a gente perca de vista algo fundamental: expressa uma tentativa de estabilizar a contínua crise de legitimidade política do neoliberalismo. Tal crise está sendo produzida com força pelo movimento feminista transnacional, plurinacional, que atualmente inventa uma politica de massas radical justamente pela sua capacidade de tramar alianças transversais que colocam em prática, de maneira concreta, seu caráter subversivo, transformador, dos modos de exploração e obediência. As alianças, como tecido político construído pacientemente em temporalidades e espaços que não costumam ser reconhecidos como estratégicos, formulam uma nova estratégia de insurreição entre xs historicamente consideradxs não cidadãos do mundo.

\section{As Entrevistadas}

Flavia Biroli é Professora de Ciência Política na Universidade de Brasília (UnB) e especialista em teoria política feminista. Em 2018, assumiu a Presidência da Associação Brasileira de Ciência Política (ABCP), com gestão até 2020, tendo coordenado até 2018, com Marlise Matos, a área temática "Gênero, democracia e políticas públicas" da entidade. Entre 2009 e 2016 foi Editora da Revista Brasileira de 
Ciência Política e é atualmente Editora Associada da Politics \& Gender. É autora de diversos livros sobre gênero e política e teoria política feminista, como as obras Autonomia e desigualdades de gênero: contribuições do feminismo para a crítica democrática, publicada em 2013 em uma parceria entre a Editora da UFF e o Editorial Horizontes, Família: novos conceitos, lançada em 2014 pela Fundação Perseu Abramo, Gênero e desigualdades: limites da democracia no Brasil, publicada em 2018 pela Editora Boitempo.

Flavia Freidenberg é Doutora em Ciência Política (2001) e Mestra em Estudos Latinoamericanos (1999) pela Universidade de Salamanca, onde atuou como Professora e Pesquisadora entre 2002 e 2015. Desde 2015 é Pesquisadora Titular do Instituto de Investigaciones Jurídicas da Universidade Nacional Autônoma do México (UNAM). É, desde 2016, Editora Associada de Política e Relações Internacionais da Latin American Research Review e coordena a Red Polítólogas. Editou recentemente dois livros: em 2017, Cuando hacer política te cuesta la vida. Estrategias contra la violencia política hacia las mujeres en América Latina - com Gabriela del Valle Pérez -, e, em 2018, Mujeres en la Política: Experiencias nacionales y subnacionales en América Latina - com Mariana Caminotti, Betilde Muñoz-Pogossian e Tomás Dosek.

Veronica Gago é Pesquisadora do Consejo Nacional de Investigaciones Científicas y Técnicas (CONICET) com sede no Instituto Interdisciplinario de Estudios de Género da Universidade de Buenos Aires (UBA) e Docente em Economia Internacional na mesma instituição. É integrante do Comitê Executivo do RC49 Socialismo, Capitalismo e Democracia, da International Political Science Association (IPSA). É também associada ao Instituto de Altos Estudos Sociais na Universidade Nacional de San Martín (UNSAM), pesquisando sobre o neoliberalismo na América Latina. Seus textos foram traduzidos a vários idiomas, a exemplo do livro "La razón neoliberal: economías barrocas y pragmática popular", publicado em 2014 pela Editora Tinta Limón e traduzido ao inglês e ao português. Com Luci Cavallero, publicou em 2019 a obra "Una lectura feminista de la deuda" pela Fundação Rosa Luxemburgo. É militante do movimento feminista argentino "Ni Una Menos". 